\title{
Использование свободного программного обеспечения в общеобразовательной школе как фактор формирования правового и технологического аспектов информационной культуры школьника
}

\author{
М.В. Маркушевич ${ }^{1}$, А.Ю. Федосов ${ }^{2}$ \\ ${ }^{1}$ ГБОУ города Москвы «Школа № 1352» \\ 2 Российский государственный социальный университет \\ mi hael11@yandex.ru, al ex_fedosov@mai I.ru
}

\section{Аннотация}

В настоящей работе авторами проведен анализ уровня сформированности «несетевого» технологического и правового аспектов информационной культуры старшеклассников, выявлен спектр проблем в области использования школьниками программного обеспечения в образовательном процессе и обосновано принципиальное значение реализации учебно-воспитательного процесса общеобразовательной школы, построенного на использовании свободного программного обеспечения, для успешного формирования правового и технологического аспектов информационной культуры учащихся.

Кроме того, в статье анализируется содержание правового и технологического аспектов информационной культуры, а также предпринимается попытка осмыслить причины возникновения проблем, существующих в сфере формирования информационной культуры школьников.

В настоящей работе предложены направления учебной и воспитательной деятельности в общеобразовательной школе, реализация которых может способствовать эффективному решению задачи формирования «несетевого» технологического и правового аспектов информационной культуры учащихся.

Ключевые слова: информационная культура, обучение и воспитание школьников, свободное программное обеспечение

Библиографическая ссылка: Маркушевич М.В., Федосов А.Ю. Использование свободного программного обеспечения в общеобразовательной школе как фактор формирования правового и технологического аспектов информационной культуры школьника // Информационное общество: образование, наука, культура и технологии будущего. Выпуск 3 (Труды XXII Международной объединенной научной конференции «Интернет и современное общество», IMS-2019, Санкт-Петербург, 19 22 июня 2019 г. Сборник научных трудов). - СПб: Университет ИТМО, 2019. C. 77 - 89. DOI: 10.17586/2587-8557-2019-3-77-89

\section{Введение}

Очевидно, что жизнь современного школьника характеризуется, в первую очередь, высокой скоростью и многопотоковостью информационных процессов, в которых он участвует. Данное обстоятельство позволяет говорить о том, что формирование информационной культуры подростка нашего времени является важнейшей задачей современного общего образования. Тематике формирования информационной культуры подрастающего поколения посвящено значительное количество научно- 
методических работ, в частности [7 - 10]. Отметим, что большинство авторов в своих работах делают акцент на компетенциях, связанных с использованием учащимся Интернета в своей жизни. Так, например, авторами исследования «Цифровая компетентность подростков и родителей», проведенного Фондом Развития Интернета и факультетом психологии МГУ имени М.В. Ломоносова, исследован уровень цифровой компетентности личности в сетевом обществе. Подробно рассматривается такие компоненты цифровой компетентности как знания, умения, мотивация и ответственность в разных сферах деятельности в интернете (работа с контентом, коммуникация, техносфера, потребление) [11].

Однако в целом можно утверждать, что наблюдается некоторый дефицит исследований в области формирования «несетевой» части информационной культуры, а именно связанной с созданием различных информационных объектов, таких как текстовые документы, мультимедийные презентации, растровые и векторные графические изображения, 3D-модели с использованием разнородных программных сред, предназначенных к применению на персональных компьютерах.

Отметим также, что в процессе исследования авторы столкнулись с весьма разноплановым пониманием самого термина «информационная культура», так, например, Семенюк Э.П. трактует данный термин как «достигнутый уровень организации информационных процессов, степень удовлетворения потребности людей в информационном общении, уровень создания, сбора, хранения, переработки и передачи информации ...» [12], Вохрышева М.Г. - как «область культуры, связанную с функционированием информации в обществе и формированием информационных качеств личности» [13], Медведева Е.А. - как «уровень знаний, позволяющий человеку свободно ориентироваться в информационном пространстве, участвовать в его формировании и способствовать информационному взаимодействию» [14].

В свою очередь Гендина Н.И. информационную культуру определяет как характеристику, присущую конкретной личности и трактует следующим образом: «Информационная культура личности - это интегративная способность личности, проявляющаяся в освоении умений по поиску, анализу и преобразованию информации на основе информационно-коммуникационных технологий и применении этих умений в обучении и дальнейшей профессиональной деятельности. Являясь одной из граней общей культуры человека, информационная культура проявляется во всех областях деятельности современного человека: учебе, работе, досуге и т.д. Информационная культура «человека учащегося» (школьника, студента, аспиранта) носит общеучебный, общеинтеллектуальный и метадпредметный характер» [1, С.15].

Другие исследователи используют вместо термина «информационная культура» другие, близкие по смыслу, в частности термин «цифровая компетентность» [11].

В свою очередь авторы настоящей работы рассматривают информационную культуру как интегральную, состоящую из многих элементов структуру, являющуюся компонентом общей культуры человека. Отметим, что информационная культура тесно связана с другими составными частями общей культуры человека (см. Таблицу 1).

Тесная взаимосвязь информационной и духовно-нравственной культуры учащихся, обусловленная используемым ими типом программного обеспечения была подробно рассмотрена ранее $[4,5]$.

В связи с отсутствием общепринятой научной терминологии и тем фактом, что информационная культура в целом является чрезвычайно сложным и многокомпонентным понятием, в настоящей статье авторы выделяют и рассматривают более узкую тематику, а именно - правовой и «несетевой» технологический аспекты информационной культуры $\mathrm{B}$ контексте их взаимосвязи $\mathrm{c}$ тем программным обеспечением, которое учащиеся используют в своей учебной и досуговой «несетевой» деятельности. 
Таблица 1. Взаимосвязь компонентов общей культуры человека и его информационной культуры

\begin{tabular}{|c|c|c|}
\hline № II/II & Вид культуры & Влияние \\
\hline 1. & $\begin{array}{l}\text { Художественная } \\
\text { культура }\end{array}$ & $\begin{array}{l}\text { Влияние обусловлено умением создавать информационные } \\
\text { объекты, соблюдая принципы эстетики, достигая максимально } \\
\text { возможного уровня гармонии и красоты. }\end{array}$ \\
\hline 2. & Правовая культура & $\begin{array}{l}\text { Влияние обусловлено пониманием и соблюдением гражданином, в } \\
\text { частности, авторского права в плане сознательного отказа от } \\
\text { использования контрафактного проприетарного программного } \\
\text { обеспечения. С другой стороны, влияние определяется умением } \\
\text { эффективно противостоять различным преступлениям с } \\
\text { использованием средств ИКТ, таким, как кража денег с } \\
\text { банковских карт и т.п. }\end{array}$ \\
\hline 3. & $\begin{array}{l}\text { Физическая } \\
\text { культура }\end{array}$ & $\begin{array}{l}\text { Влияние обусловлено умением использовать информационные } \\
\text { технологии, не причиняя вреда собственному здоровью или, по } \\
\text { возможности, минимизируя вредное влияние, соблюдая правила } \\
\text { безопасного использования аппаратных средств ИКТ. }\end{array}$ \\
\hline 4. & $\begin{array}{l}\text { Духовно- } \\
\text { нравственная } \\
\text { культура }\end{array}$ & $\begin{array}{l}\text { В данном случае влияние многофакторное, может заключаться: } \\
-\quad \text { В умении и решимости не интересоваться и не использовать } \\
\text { негативный контент в Интернете (насилие, терроризм, } \\
\text { порнография, суицидальная направленность), а также } \\
\text { использовать его фильтрование для детей; } \\
\text { В умении не использовать навязываемое в процессе обучения } \\
\text { в некоторых образовательных организациях проприетарное } \\
\text { программное обучение, а применять доступные свободные } \\
\text { аналоги. }\end{array}$ \\
\hline
\end{tabular}

Под правовым аспектом информационной культуры индивида будем понимать совокупность знаний и умений по эффективной информационной деятельности, не вступающей в конфликт с законодательством Российской Федерации в области защиты авторского права, информационной безопасности и неприкосновенности частной жизни.

Под «несетевым» технологическим аспектом правовой культуры индивида будем понимать совокупность знаний и умений по эффективной информационной деятельности в области создания различных информационных объектов наиболее оптимальным способом. Наиболее оптимальным способом создания некого информационного объекта, с точки зрения авторов, является такая технология, которая требует наименьших возможных материальных и временных затрат, а также не связана с нарушением законодательства Российской Федерации в области защиты авторского права.

Таким образом, целью настоящего исследования является оценка уровня сформированности технологического и правового аспекта информационной культуры «несетевой» деятельности старшеклассников общеобразовательной школы.

\section{Задачи исследования:}

1. Провести диагностику уровня сформированности технологического и правового аспекта информационной культуры старшеклассников.

2. Провести статистическую обработку полученных эмпирических результатов исследования.

3. Провести анализ результатов диагностики уровня сформированности технологического и правового аспекта информационной культуры старшеклассников.

4. Уточнить определения понятий «технологический и правовой аспект информационной культуры», а также раскрыть их содержание в плане «несетевой» информационной культуры. 
5. Сформулировать рекомендации по возможным направлениям повышения уровня сформированности технологического и правового аспекта информационной культуры старшеклассников.

\section{1. Гипотеза, методология и методика исследования}

При разработке концепции настоящего исследования авторы исходили, в том числе, из выводов, сделанных Фондом Развития Интернета в своем анализе «Цифровая компетентность подростков и родителей» «В среднем уровень цифровой компетентности как родителей подростков, так и самих подростков составляет в России примерно треть от максимально возможного (31\% у родителей и $34 \%$ у подростков)» $[11$, с. 6]. В данном исследовании речь идет о «сетевом» элементе информационной культуры подростков, который, как мы постараемся показать ниже, требует ИКТ-компетенций более низкого уровня, чем «несетевой» элемент. Рассматриваемое предположение основывается на том факте, что «несетевые» ИКТ-компетенции являются потенциально более сложными по сравнению с «сетевыми», что может быть объяснено большим количеством программных сред, имеющих достаточно многофункциональный пользовательский интерфейс, и предполагающих применение многоитерационных алгоритмов создания информационных объектов различного типа (например, многостраничных текстовых документов, содержащих форматированный текст, таблицы, рисунки, списки, автоматическое оглавление и т.п.).

Интерфейс Web-приложений обычно сравнительно проще и предполагает весьма ограниченный инструментарий, состоящий из управляющих кнопок, открывающихся списков, переключателей, текстовых полей и т.п.

В плане формирования правового аспекта информационной культуры школьников можно отметить достаточно тревожные оценки ряда авторов, например, Постникова А.В. в своей работе «Мониторинг и диагностика результатов в области гражданско-правового образования несовершеннолетних» отмечает следующее: «Характерными особенностями несовершеннолетних становится правовой нигилизм, недостаточный уровень правовой культуры, культуры в целом ...» $[15$, с. 1]. В другом исследовании уровня правовой культуры одиннадцатиклассников, проведенном Игошиной Н.В. и Долбиловым С.В. дается несколько более оптимистическая оценка, а именно - только у $50 \%$ учащихся наблюдается мотивация правового поведения [16]. Близкой позиции придерживается авторский коллектив из Республики Татарстан, возглавляемый Гафуровым И.Р., в социологическом исследовании которого, в частности, отмечается: «Две трети опрошенных вполне терпимо относятся к тем, кто нарушает законы и общественный порядок. Осуждает их лишь каждый ... четвертый школьник ...» [17].

Таким образом, на основании вышесказанного, была сформулирована следующая гипотезу исследования: уровень правового и «несетевого» технологического аспекта информационной культуры учащихся общеобразовательной школы может быть не выше $40 \%$ от максимально возможного для данного возраста значения.

В настоящей работе авторы поставили целью провести диагностику уровня сформированности технологического и правового аспекта информационной культуры старшеклассников.

Для диагностики уровня сформированности технологического аспекта информационной культуры можно использовать как прямой, так и косвенный методы, заключающиеся в следующем.

Прямой метод состоит в том, что учащиеся в качестве тестового задания создают сложный информационный объект, предполагающий использование нескольких программных сред, например, многостраничный текстовый документ, содержащий изображение объемной фигуры с нанесенными на него размерами, расчет объема и площади поверхности данной фигуры в электронных таблицах. Подробно данная методика 
описана в [3]. Очевидно, что прямой метод диагностики обладает высокой точностью и информативностью, но предполагает проведение довольно трудозатратного тестирования учащихся.

Косвенный метод диагностики может, в частности, заключаться в тестировании учащихся на знание прикладного программного обеспечения различного типа, используемого в учебно - воспитательном процессе общеобразовательных школ, а именно: текстовых редакторов, электронных таблиц, векторных и растровых графических редакторов, систем компьютерного черчения, звуковых и видеоредакторов и т.п. Действительно, первичным уровнем сформированности технологического аспекта информационной культуры можно считать наличие у учащихся кругозора в области прикладного программного обеспечения различных типов, понимание преимуществ и недостатков конкретного ПО, знание альтернативных вариантов для ПО каждого из рассмотренных типов.

Например, при изучении темы курса информатики основной школы «Создание и обработка текстовой информации» можно говорить о сформированности первичного уровня технологического аспекта информационной культуры в том случае, если тестируемые учащиеся знают свободные текстовые редакторы OpenOffice.org Writer и LibreOffice Writer, а также проприетарный текстовый редактор Microsoft Word, понимают разницу в условиях лицензирования на упомянутое выше программное обеспечение, знают пути их приобретения и варианты операционных систем, под которыми возможна их установка на персональный компьютер.

Таким образом, так как в гипотезе настоящего исследования предполагается изначально невысокий уровень сформированности технологического аспекта информационной культуры, то для его диагностики вполне можно воспользоваться менее точным косвенным методом.

Диагностика проводилась путем анализа результата входного контроля знаний учащихся десятых классов общеобразовательных школ города Москвы по теме «Информация», в котором предполагалось указать известное им программное обеспечение. Результаты входного контроля по всем десятым классам были подвергнуты сравнению с использованием U-критерия Манна-Уитни. Данный критерий предназначен для оценки различий между двумя выборками по уровню какого-либо признака, количественно измеренного. В нашем случае речь идет про анализ частоты перечисления учащимися определенного вида программного обеспечения. В результате статистической обработки можно говорить об отсутствии значимых различий между результатами входного контроля всех десятых классов. Наиболее характерный список упоминаемого старшеклассниками программного обеспечения приведен в Таблице 2.

Таблица 2. Используемое на практике программное обеспечение, известное старшеклассникам, а также ПО, соответствующий полностью сформированному первичному уровню технологического аспекта информационной культуры

\begin{tabular}{|c|l|l|l|}
\hline \multirow{2}{*}{ № } & $\begin{array}{c}\text { Тип программного } \\
\text { обеспечения }\end{array}$ & $\begin{array}{c}\text { Известное } \\
\text { учащимся } \\
\text { программное } \\
\text { обеспечение }\end{array}$ & $\begin{array}{c}\text { Список программного обеспечения, } \\
\text { соответствующий полностью } \\
\text { сформированному первичному } \\
\text { уровню «несетевого» } \\
\text { технологического аспекта } \\
\text { информационной культуры }\end{array}$ \\
\hline 1. & Текстовые редакторы & $\begin{array}{l}\text { Microsoft Word } \\
\text { Блокнот }\end{array}$ & $\begin{array}{l}\text { OpenOffice.org Writer } \\
\text { LibreOffice Writer } \\
\text { Microsoft Word }\end{array}$ \\
\hline 2. & Электронные таблицы & Microsoft Excel & $\begin{array}{l}\text { OpenOffice.org Calc } \\
\text { LibreOffice Calc } \\
\text { Microsoft Excel }\end{array}$ \\
\hline
\end{tabular}




\begin{tabular}{|c|c|c|c|}
\hline № & $\begin{array}{l}\text { Тип программного } \\
\text { обеспечения }\end{array}$ & $\begin{array}{c}\text { Известное } \\
\text { учащимся } \\
\text { программное } \\
\text { обеспечение }\end{array}$ & $\begin{array}{c}\text { Список программного обеспечения, } \\
\text { соответствующий полностью } \\
\text { сформированному первичному } \\
\text { уровню «несетевого» } \\
\text { технологического аспекта } \\
\text { информационной культуры } \\
\end{array}$ \\
\hline 3. & $\begin{array}{l}\text { Программы для создания } \\
\text { презентаций }\end{array}$ & $\begin{array}{l}\text { Microsoft } \\
\text { PowerPoint }\end{array}$ & $\begin{array}{l}\text { OpenOffice.org Impress, LibreOffice } \\
\text { Impress, Microsoft PowerPoint }\end{array}$ \\
\hline 4. & $\begin{array}{l}\text { Программы для } \\
\text { редактирования фотографий }\end{array}$ & $\begin{array}{l}\text { Adobe } \\
\text { Photoshop }\end{array}$ & GIMP, Krita, Picasa, Adobe Photoshop \\
\hline 5. & Программы для рисования & $\begin{array}{l}\text { Paint, Adobe } \\
\text { Photoshop }\end{array}$ & $\begin{array}{l}\text { GIMP, Krita, Picasa, OpenOffice.org } \\
\text { Draw, LibreOffice Draw, Adobe } \\
\text { Photoshop, Paint }\end{array}$ \\
\hline 6. & $\begin{array}{l}\text { Программы для } \\
\text { редактирования } \\
\text { (обработки)звука }\end{array}$ & $\begin{array}{l}\text { В основном } \\
\text { затрудняются } \\
\text { ответить } \\
\end{array}$ & Audacity, Sound Forge Pro \\
\hline 7. & $\begin{array}{l}\text { Программы для } \\
\text { редактирования } \\
\text { (обработки)видео }\end{array}$ & $\begin{array}{l}\text { Sony Vegas } \\
\text { Pro, Movavi, } \\
\text { Windows } \\
\text { Movie Maker }\end{array}$ & $\begin{array}{l}\text { Shotcut, OpenShot, Sony Vegas Pro, } \\
\text { Movavi, Windows Movie Maker }\end{array}$ \\
\hline 8. & $\begin{array}{l}\text { Программы для создания баз } \\
\text { данных }\end{array}$ & Microsoft Excel & $\begin{array}{l}\text { OpenOffice.org Base, LibreOffice Base, } \\
\text { OpenOffice.org Calc, LiberOffice Calc, } \\
\text { MySQL, Microsoft Excel }\end{array}$ \\
\hline 9. & $\begin{array}{l}\text { Программы для } \\
\text { компьютерного черчения }\end{array}$ & $\begin{array}{l}\text { В основном } \\
\text { затрудняются } \\
\text { ответить }\end{array}$ & FreeCad, Компас 3D, Autocad \\
\hline 10. & Операционные системы & $\begin{array}{l}\text { Microsoft } \\
\text { Windows, } \\
\text { Android, iOS }\end{array}$ & $\begin{array}{l}\text { Linux, Mac OS X, Microsoft Windows, } \\
\text { Android, iOS. }\end{array}$ \\
\hline 11. & $\begin{array}{l}\text { Общее количество указанных } \\
\text { программ }\end{array}$ & 14 & 41 \\
\hline
\end{tabular}

Анализ уровня сформированности правового аспекта информационной культуры проводился авторами также на основании результатов входного контроля знаний учащихся десятых классов. Входной контроль включал в себя вопросы, перечисленные в Таблице 3.

Таблица 3. Вопросы входного контроля, касающиеся правовых аспектов информационной культуры

\begin{tabular}{|l|l|l|}
\hline № & \multicolumn{1}{|c|}{ Вопрос } & \multicolumn{1}{|c|}{\begin{tabular}{c}
\multicolumn{1}{|c|}{ \% } \\
правильных \\
ответов
\end{tabular}} \\
\hline 1. & $\begin{array}{l}\text { В чем разница, с вашей точки зрения, между платным и свободным } \\
\text { программным обеспечением? }\end{array}$ & 38 \\
\hline 2. & $\begin{array}{l}\text { Знаете ли вы какая ответственность предусмотрена за использование } \\
\text { контрафактных экземпляров лицензионного программного обеспечения (за } \\
\text { установку на компьютер нелицензионных программ)? }\end{array}$ & 28 \\
\hline 3. & $\begin{array}{l}\text { Какие программы из используемых вами на уроках информатики в школе } \\
\text { относятся к проприетарному программному обеспечению? }\end{array}$ & 24 \\
\hline 4. & $\begin{array}{l}\text { Какие программы из используемых вами на уроках информатики в школе } \\
\text { относятся к свободному программному обеспечению? }\end{array}$ & 24 \\
\hline
\end{tabular}




\section{2. Интерпретация представленных данных}

По результатам проведенного анализа итогов входного тестирования можно сделать следующие выводы:

1. Старшеклассникам известен крайне ограниченный набор программного обеспечения (34\% от минимального базового списка, при владении которого можно говорить о полностью сформированном первичном уровне «несетевого» технологического аспекта информационной культуры), перечисленный в Таблице 2, в основном проприетарного типа.

2. Учащиеся часто затрудняются идентифицировать то или иное программное обеспечение как свободное или проприетарное.

3. Учащиеся часто затрудняются определить, для чего используется то или иное программное обеспечение.

4. Учащиеся лучше ориентируются в программном обеспечении, предназначенном для использования под мобильными операционными системами (Android, iOS), чем под операционными системами, используемыми на настольных конфигурациях персональных компьютеров (Windows, Linux, Mac OS X).

5. Учащиеся не вполне серьезно воспринимают для себя перспективу административной и уголовной ответственности в случае использования контрафактного проприетарного программного обеспечения в своей учебной и досуговой деятельности.

Надо отметить, что в научно-педагогической литературе практически не представлены исследования в области анализа, используемого учащимися общеобразовательных школ программного обеспечения, однако в ряде публикаций в материалах региональных конференций отмечается низкий уровень правового аспекта информационной культуры учащихся в аспекте использования программного обеспечения. Главным образом причинами этого явления являются:

1. Недостаточная просветительская работа по популяризации использования свободного программного обеспечения для решения учащимися стоящих перед ними учебных задач;

2. Низкий порог восприятия риска совершения противоправного действия, антисоциального поведения у подростков [2].

На психофизиологические особенности подросткового возраста, как на причину рискованного в правовом смысле поведения указывается, в частности, в работе А.И. Юдиной: «Причины эти скрыты в особенностях возраста: импульсивности, экстраверсии, эмоциональной неустойчивости, стремлении расширить границы дозволенного» [6, с. 149].

Далее хотелось бы отметить, что, технологический аспект информационной культуры является более широким понятием по отношению к ИКТ-компетентности. ИКТ-компетентность индивида является интегральной характеристикой, объединяющей в себе некий обширный набор частных ИКТ-компетенций в различных областях применения информационных технологий. Так, например, можно выделить набор ИКТкомпетенций в области создания и обработки текстовой информации (Таблица 4).

Обратим внимание на тот факт, что человека можно считать компетентным в области создания и обработки текстовой информации в том случае, если у него в достаточной мере сформированы перечисленные компетенции, вне зависимости от того, какой именно текстовый редактор он при этом использует. Говорить о наличии сформированного технологического аспекта информационной культуры, по глубокому убеждению авторов, можно только в том случае, если, кроме присутствия ИКТ-компетенций в определенной области, человек способен создавать искомый информационный объект оптимальным способом, т.е. с наименьшими материальными и временными затратами и не вступая в конфликт с законодательством Российской федерации. 
Таблица 4. ИКТ-компетенции в области обработки текстовой информации

\begin{tabular}{|l|l|}
\hline \multicolumn{1}{|c|}{ № } & \multicolumn{1}{|c|}{ ИкТ-компетенции в области обработки текстовой информации } \\
\hline 1. & $\begin{array}{l}\text { Умение набирать русский текст, форматировать символы (гарнитура шрифта, размер } \\
\text { кегля, цвет шрифта, начертание, нижний и верхний индексы, текстовые эффекты) }\end{array}$ \\
\hline 2. & $\begin{array}{l}\text { Умение сохранять созданный текстовый файл в указанном месте файловой системы и в } \\
\text { заданном формате }\end{array}$ \\
\hline 3. & $\begin{array}{l}\text { Умение форматировать абзацы (выравнивание, отступ слева и справа, первая строка, } \\
\text { межстрочный интервал, интервалы перед и после абзаца) }\end{array}$ \\
\hline 4. & $\begin{array}{l}\text { Умение форматировать страницы (формат страницы, ориентация, поля страницы, фон } \\
\text { страницы, нижний и верхний колонтитулы, нумерация страниц) }\end{array}$ \\
\hline 5. & $\begin{array}{l}\text { Умение редактировать текст, выполнять операции копирования, вырезания, перемещения } \\
\text { и вставки фрагмента текста. }\end{array}$ \\
\hline 6. & $\begin{array}{l}\text { Умение создавать одноуровневые и многоуровневые маркированные и нумерованные } \\
\text { списки, форматировать их. }\end{array}$ \\
\hline 7. & Умение вставлять в текстовый документ рисунки, форматировать их \\
\hline 8. & $\begin{array}{l}\text { Умение создавать и вставлять в текстовый документ таблицы, форматировать их, } \\
\text { объединять и разделять ячейки, менять тип отображение границ таблицы }\end{array}$ \\
\hline 9. & $\begin{array}{l}\text { Умение вставлять в текст математические формулы с помощью редактора формул } \\
\text { ОрепОffiсе.огg Матh }\end{array}$ \\
\hline 10. & $\begin{array}{l}\text { Умение вставлять в текст автоматическое оглавление документа, использовать стили } \\
\text { форматирования }\end{array}$ \\
\hline
\end{tabular}

Проиллюстрируем приведенное выше утверждение следующим примером. Предположим, перед человеком стоит задача создать некий коллаж из нескольких растровых изображений, причем данная задача не является его постоянной работой, а возникла единовременно. Можно предложить два следующих возможных алгоритма решения поставленной задачи (см. Таблицу 5).

Таблица 5. Варианты решения задачи создания коллажа

\begin{tabular}{|c|c|c|}
\hline & Алгоритм № 1 & Алгоритм № 2 \\
\hline Алгоритм & 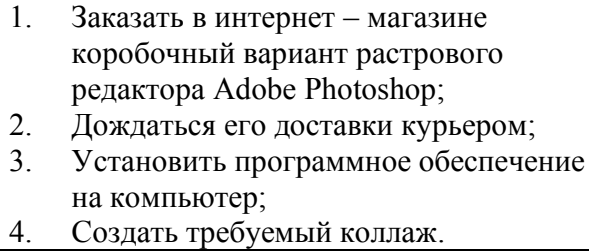 & $\begin{array}{l}\text { 1. Скачать с официального сайта } \\
\text { gimp.org свободный } \\
\text { растровый графический } \\
\text { редактор GIMP; } \\
\text { 2. Установить его на компьютер; } \\
\text { 3. Создать требуемый коллаж. }\end{array}$ \\
\hline $\begin{array}{l}\text { Стоимость } \\
\text { реализации } \\
\text { алгоритма }\end{array}$ & Примерно 25000 рублей. & Бесплатно. \\
\hline $\begin{array}{l}\text { Время } \\
\text { реализации } \\
\text { алгоритма }\end{array}$ & $2-3$ дня & $1-2$ часа \\
\hline
\end{tabular}

Хотя оба приведенных выше алгоритма достигают поставленной задачи, но достаточно сложно говорить о наличии сформированного технологического аспекта информационной культуры у человека, реализующего алгоритм № 1 на практике.

В полной мере содержание технологического аспекта информационной культуры раскрывается в том случае, когда стоит задача создания сложного информационного объекта, алгоритм разработки которого предполагает использование нескольких различных программных сред. В качестве примера такого объекта приведем текстовый документ, содержащий изображение объемной фигуры, показанное на рисунке 1 , а также расчет ее объема и площади поверхности в электронных таблицах. 


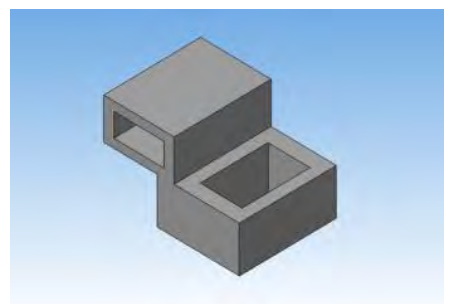

Рис. 1. Объемная фигура

Разрабатываемый в данном случае оптимальный алгоритм будет достаточно близок к следующему:

1. Построить трехмерную модель фигуры в системе компьютерного черчения Компас (рисунок 1).

2. Сохранить ее изображение, нанести на него размеры с помощью растрового графического редактора GIMP.

3. Вставить изображение детали в текстовый документ в текстовом редакторе OpenOffice.org Writer.

4. Набрать формулы для расчета объема и площади поверхности рассматриваемой фигуры с помощью редактора математических формул OpenOffice.org Math.

5. Вставить электронную таблицу OpenOffice.org Calc в виде объекта OLE в текстовый документ, ввести необходимые формулы для расчета значений объема и площади поверхности рассматриваемой трехмерной фигуры.

6. Сохранить текстовый документ.

Приведенный выше алгоритм предполагает последовательное использование пяти различных программных сред, которые могут быть следующими:

1. Облегченная бесплатная версия для учебных целей системы трехмерного моделирования (компьютерного черчения) Компас-3D LT;

2. Свободный растровый графический редактор GIMP 2;

3. Свободный текстовый редактор OpenOffice.org Writer;

4. Свободный редактор математических формул OpenOffice.org Math;

5. Свободные электронные таблицы OpenOffice.org Calc [3].

\section{Выводы}

На основании приведённого выше примера можно говорить о следующих составляющих технологического компонента информационной культуры:

- основательный кругозор в области свободного и проприетарного программного обеспечения;

- понимание достоинств и недостатков различных типов программного обеспечения;

- умение построить оптимальный алгоритм создания сложного информационного объекта с использованием различных программных инструментов.

Правовой аспект информационной культуры включает в себя следующие компоненты.

Ясное понимание существования двух различных идеологий разработки и распространения программного обеспечения, заключающихся: в существовании собственника какого-либо программного обеспечения и ситуации, когда другие люди покупают у него лицензию на право использования данного программного обеспечения; программное обеспечение разрабатывается коллективом единомышленников и передается в открытое использование всем желающим, которые помогают в процессе развития свободного программного обеспечения; 
Умение различать свободную и платную лицензию на использование программного обеспечения, а также разбираться в нюансах и ограничениях данных лицензий; Знание меры ответственности, предусмотренной за использование контрафактных экземпляров лицензионного программного обеспечения;

Умения отстаивания своих прав на изучение в образовательной организации свободного программного обеспечения, а не платных программ, за использование которых в своей будущей жизни после окончания школы необходимо будет платить из своих средств.

Анализ уровня сформированности «несетевого» технологического и правового аспектов информационной культуры у учащихся общеобразовательных российских школ говорит о наличии проблемы, причинами которой являются:

1. Использование учащимися в основном мобильных аппаратных средств в досуговой деятельности и, как следствие, недостаточный уровень компетенций и узкий кругозор в области применения полнофункционального программного обеспечения, предназначенного для настольных персональных компьютеров;

2. Недостаточная просветительская работа по популяризации использования свободного программного обеспечения для решения учащимися стоящих перед ними учебных задач в общеобразовательной российской школе;

3. Наличие у подростков низкого порога восприятия риска совершения противоправных действий, антисоциального поведения, не полностью компенсируемый соответствующей разъяснительной работой, направленной на повышение правовой грамотности в области соблюдения авторского права.

Вышеуказанные проблемы в области формирования информационной культуры учащихся могут быть успешно разрешены с помощью реализации в образовательном процессе общеобразовательной школы следующих направлений учебной и воспитательной деятельности:

1. Миграции учебного процесса общеобразовательной российской школы на свободное программное обеспечение (в том числе российской разработки);

2. Усиление просветительской работы в области правовой грамотности учащихся и предотвращения различных форм аддикций, связанных с чрезмерным и не учебным использованием мобильных средств ИКТ;

3. Активное использование в учебном процессе как по информатике, так и по другим школьным предметам, практических домашних заданий и проектных работ, в ходе которых учащиеся создают сложные информационные объекты, используя несколько различных полнофункциональных программных сред.

\section{Литература}

[1] Гендина Н.И. Информационная культура личности в системе образования информационного общества: реализация научного наследия С.А. Сбитнева // Вестник Кемеровского государственного университета культуры и искусств. 2018. № 42. С. 13 19.

[2] Лакреева А.В., Варуха Л.В. Склонность к риску как фактор девиантного поведения подростков // Концепт. 2016. T. 24. C. 141-146. URL: http://e-koncept.ru/2016/56427.htm (дата обращения: 27.02.2019).

[3] Маркушевич М.В. Полипрограммные интегрированные уроки на базе свободного программного обеспечения как средство контроля ИКТ-компетенций старших школьников // Информатика в школе. 2017. №4 (127). С. 12 - 17.

[4] Федосов А.Ю., Маркушевич М.В. Применение свободного программного обеспечения в учебном процессе как фактор духовно-нравственного воспитания учащихся // Информатика в школе. 2018. № 4. С. 40-43.

[5] Федосов А.Ю., Маркушевич М.В. Использование отечественного и свободного программного обеспечения в образовательном процессе как фактор духовно- 
нравственного воспитания младших школьников // Герценовские чтения. Начальное образование. 2018. Т. 9. № 1. С. 27-35.

[6] Юдина А.И. Досуговые предпочтения современных подростков: предупреждение социальных рисков // Вестник Кемеровского государственного университета культуры и искусств. 2017. № 38. С. 146-151.

[7] Соловьёва Т.А., Максимова Е.В. Структурные компоненты и функции информационной культуры школьника // Современные проблемы образования в поликультурном регионе (Шестые Лозинские чтения) Материалы Международной научно-методической конференции. Ответственный за выпуск Н.Ю. Шлат. 2015. С. 174-184.

[8] Желтова И.А. Сетевая культура школьников как часть информационной культуры личности // Проблемы и перспективы развития образования в России. 2013. № 19. С. 213-218.

[9] Хайбулаев М.Х., Исламова С.Х. Структура и компоненты информационной культуры школьников // Известия Дагестанского государственного педагогического университета. Психолого-педагогические науки. 2015. № 2 (31). С. 68-73.

[10]Грандова С.И. Информационная культура школьника: проблемы и перспективы // Конференциум АСОУ: сборник научных трудов и материалов научно-практических конференций. 2017. № 4. С. 66-69.

[11]Солдатова Г.У. Цифровая компетентность подростков и родителей. Результаты всероссийского исследования / Г.У. Солдатова, Т.А. Нестик, Е.И. Рассказова, Е.Ю. Зотова. - М.: Фонд Развития Интернет, 2013. 144 с.

[12]Семенюк Э.П. Глобализация и социальная роль информатики // Науч.-техн. информ. Сер. 1. Орг. и методика информ. работы. 2003. № 1. С. 1-10.

[13]Вохрышева М.Г. Формирование науки об информационной культуре // Проблемы информационной культуры: сб. ст. Вып. 6. Методология и организация информационно-культурологических исследований / науч. ред.: Ю.С. Зубов, В.А. Фокеев. - М., 1997.

[14]Медведева Е.А. Основы информационной культуры // Социс. 1994. № 11.

[15]Постникова А.В. Мониторинг и диагностика результатов в области гражданскоправового образования несовершеннолетних. URL: https://scienceforum.ru/2016/article/2016023557 (дата обращения: 8.06.2019).

[16]Игошина Н. В., Долбилов С. В. Формирование правовой культуры школьника // Научно-методический электронный журнал «Концепт». 2016. Т. 15. С. 1941-1945.

[17]Гафуров И.Р., Исламшина Т.Г., Нургатина Л.А., Куппер Е.В., Хамзина Г.Р. Факторы девиантного поведения провинциальной молодежи (опыт социологического исследования) // Интеграция образования. 2004. № 2 (35). С. 114-118.

\title{
The Use of Free Software in the Secondary School as a Factor in the Formation of the Legal and Technological Aspects of the Student's Information Culture
}

\author{
M. Markushevich ${ }^{1}$, A. Fedosov ${ }^{2}$
}

${ }^{1}$ School 1352, ${ }^{2}$ Russian Social State University

The article presents new approaches to the problem of adaptation of the computer system in the individual testing of students in distance learning in the training of bachelors. The features of the presentation of educational content, adaptive algorithm for individual testing of educational achievements of students. The model of realization of adaptivity based on usage of possibilities of computer system for the purpose of more absolute realization of personalized approach in 
computer-based learning is proposed. The peculiarities of presentation of training content, structuring of test materials and also adaptive algorithm of individual testing of studying achievements of a student, considering essential characteristics of computer process of knowledge assessment and making it possible to widely introduce it into the systems of distance learning are analyzed.

Keywords: distance learning; adaptation; computer testing; the testing algorithm

Reference for citation: Markushevich M., Fedosov A. The Use of Free Software in the Secondary School as a Factor in the Formation of the Legal and Technological Aspects of the Student's Information Culture // Information Society: Education, Science, Culture and Technologies of the Future. Vol. 3 (Proceedings of the XXII International Joint Scientific Conference «Internet and Modern Society», IMS-2019, St. Petersburg, June 19-22, 2019). St. Petersburg: ITMO University, 2019. P. 77 - 89. DOI: 10.17586/2587-8557-2019-3-77-89

\section{Reference}

[1] Gendina N.I. Informacionnaya kul'tura lichnosti v sisteme obrazovaniya informacionnogo obshchestva: realizaciya nauchnogo naslediya S.A. Sbitneva. // Vestnik Kemerovskogo gosudarstvennogo universiteta kul'tury $i$ iskusstv. 2018. № 42. P. 13-19.

[2] Lakreeva A.V., Varuha L.V. Sklonnost' k risku kak faktor deviantnogo povedeniya podrostkov // Koncept. 2016. T. 24. P. 141-146. URL: http://e-koncept.ru/2016/56427.htm (data obrashcheniya: 27.02.2019).

[3] Markushevich M.V. Poliprogrammnye integrirovannye uroki na baze svobodnogo programmnogo obespecheniya kak sredstvo kontrolya IKT-kompetencij starshih shkol'nikov // Informatika v shkole. 2017. №4 (127). P. 12 - 17.

[4] Fedosov A.Yu., Markushevich M.V. Primenenie svobodnogo programmnogo obespecheniya $\mathrm{v}$ uchebnom processe kak faktor duhovno-nravstvennogo vospitaniya uchashchihsya // Informatika v shkole. 2018. № 4. P. 40-43.

[5] Fedosov A.Yu., Markushevich M.V. Ispol'zovanie otechestvennogo i svobodnogo programmnogo obespecheniya $\mathrm{V}$ obrazovatel'nom processe kak faktor duhovnonravstvennogo vospitaniya mladshih shkol'nikov // Gercenovskie chteniya. Nachal'noe obrazovanie. 2018. T. 9. № 1. P. 27-35.

[6] Yudina A.I. Dosugovye predpochteniya sovremennyh podrostkov: preduprezhdenie social'nyh riskov // Vestnik Kemerovskogo gosudarstvennogo universiteta kul'tury i iskusstv. 2017. № 38. P. 146-151.

[7] Solov'yova T.A., Maksimova E.V. Strukturnye komponenty i funkcii informacionnoj kul'tury shkol'nika // V sbornike: Sovremennye problemy obrazovaniya v polikul'turnom regione (SHestye Lozinskie chteniya) Materialy Mezhdunarodnoj nauchno-metodicheskoj konferencii. Otvetstvennyj za vypusk N.YU. SHlat. 2015. P. 174-184.

[8] ZHeltova I.A. Setevaya kul'tura shkol'nikov kak chast' informacionnoj kul'tury lichnosti // Problemy i perspektivy razvitiya obrazovaniya v Rossii. 2013. № 19. P. 213-218.

[9] Hajbulaev M.H., Islamova S.H. Struktura i komponenty informacionnoj kul'tury shkol'nikov // Izvestiya Dagestanskogo gosudarstvennogo pedagogicheskogo universiteta. Psihologopedagogicheskie nauki. 2015. № 2 (31). P. 68-73.

[10]Grandova S.I. Informacionnaya kul'tura shkol'nika: problemy i perspektivy. Konferencium ASOU: sbornik nauchnyh trudov i materialov nauchno-prakticheskih konferencij. 2017. № 4. P. 66-69.

[11]Soldatova G.U. Cifrovaya kompetentnost' podrostkov i roditelej. Rezul'taty vserossijskogo issledovaniya / G.U. Soldatova, T.A. Nestik, E.I. Rasskazova, E.YU. Zotova. - M.: Fond Razvitiya Internet, 2013. - 144 p.

[12] Semenyuk E.P. Globalizaciya i social'naya rol' informatiki // Nauch.-tekhn. inform. Ser. 1. Org. i metodika inform. raboty. - 2003. - № 1. - P. 1-10. 
[13] Vohrysheva M.G. Formirovanie nauki ob informacionnoj kul'ture // Problemy informacionnoj kul'tury : sb. st. Vyp. 6. Metodologiya i organizaciyainformacionnokul'turologicheskih issledovanij / nauch. red.: YU.S. Zubov, V.A. Fokeev. - M., 1997.

[14] Medvedeva E.A. Osnovy informacionnoj kul'tury // Socis. - 1994. - № 11.

[15] Postnikova A.V. Monitoring i diagnostika rezul'tatov v oblasti grazhdansko-pravovogo obrazovaniya nesovershennoletnih / [Elektronnyj resurs]. - Rezhim dostupa: https://scienceforum.ru/2016/article/2016023557 (data obrashcheniya: 8.06.2019).

[16] Igoshina N. V., Dolbilov S. V. Formirovanie pravovoj kul'tury shkol'nika // Nauchnometodicheskij elektronnyj zhurnal «Koncept». - 2016. - T. 15. - P. 1941-1945.

[17] Gafurov I.R., Islamshina T.G., Nurgatina L.A., Kupper E.V., Hamzina G.R. Faktory deviantnogo povedeniya provincial'noj molodezhi (opyt sociologicheskogo issledovaniya) // Integraciya obrazovaniya. 2004. № 2 (35). P. 114-118. 